\title{
IMPLICATIONS OF MIDDLEMEN IN THE SUPPLY CHAIN OF AGRICULTURAL PRODUCTS
}

\author{
${ }^{1}$ OGUOMA, O.N., ${ }^{2}$ V. I. NKWOCHA*, AND ${ }^{3}$ I. I. IBEAWUCHI. \\ ${ }^{1}$ Department of Mechanical Engineering, \\ Fed. Univ. of Tech. Owerri, Imo State, Nigeria \\ ${ }^{2}$ Centre for Agric. Research Fed. Univ. of Tech. Owerri, Nigeria \\ ${ }^{3}$ Department of Crop Science \& Tech, Fed. Univ. of Tech. Imo State, Nigeria \\ *Corresponding author, email: iyke_nkwocha@yahoo.com
}

\begin{abstract}
This paper appraised the roles of middlemen in the distribution of agricultural products and the inherent implications to food security. The results showed that climate and weather are known limiting factors of production in agriculture. Also, middlemen intervention raise price for consumers. The result showed that farmers encounter high production costs in their efforts to boost production but hardly get fair pricing of their products from the middlemen, the bulk farm gate buyers. The real profit goes to the middlemen who buy up the farm products at almost give away prices and sell at outrageous prices to the consumers. This attitude of middle men have discouraged genuine investors getting into agriculture because of the marginal profit associated with it as the middle men cart away the bulk of the profits. Thus, the activities of middlemen seem to be a threat to food security.
\end{abstract}

Keywords: marketing, agricultural products, food security.

\section{INTRODUCTION}

Middlemen operate in all the continents of the world especially where the economy is booming. These groups of people act as intermediary between the producers (farmers) and the consumers. In the process of letting food or other agricultural materials reach the final consumer (user), the price is marked up to cover transportation, storage and profit. Food insecurity is one of the problems in sub Saharan Africa as a result of many environmental factors including human.

According to Esonu, (2009), food security implies having physical and economic access to food that is adequate in terms of quality, quantity and safety. Food security can be described as "when all people at all times have physical and economic access to sufficient food to meet their dietary need for productive and healthy life (USAID, 1995) Hence, food security does not mean making food available alone, it is the guarantee of making the healthy and nutrient food available and accessible for all the needy people at local level and at affordable prices. Food security undoubtedly is a broad and complex concept that is determined by agro-ecological, agro-physical, socio-economic and biological factors (Campbell, 1991; Von Braun et al, 1992). However, Asiabaka, (2010), defined food security by a triad of concepts; food availability, food access and food utilization. The global food record shows that over 850 million people in the world are undernourished. About 15 per cent of the World population consume more than 60 per cent of the food produced and distributed, while the remaining 85 per cent live on less than 40 per cent of food the world produces (Yuba, 2007). This is in agreement in the negative sense with Pareto's principle of the very important few and insignificant majority. The situation, thus, portends danger and underscores the dire need for taking more concerted and critical measures for food security as the world gears up to meet the millennium development goals by 2015 of providing for the majority. Furthermore, it would be a mirage for the global community to achieve the lofty goal of meeting the minimum basic needs of people by 2015 with the level of poverty and 
hunger in Africa worsened by the food and resources distribution mechanisms. Farmers are slowly loosing interest in agriculture due to low productivity and high costs of production and the food growers are either switching over to high-value cash crops from the food grain production or seeking an alternative profession. Farmers hardly get real profit for their products, even when they sell at considerable prices; the products are disappointedly given at outrageous prices to the consumers. Neither farmers nor the consumers benefit but rather the middlemen due to farm gate prices benefit from the toil of the farmers.

The middlemen for their high profit margin dictate the prices of these food items especially in the urban areas where there is a large pool of well to do who can easily afford the prices. By the time a portion of their goods are sold at the dictated prices, they have recovered their principals and adequate profits. They still insist on the prices until spoilage sets in and the items rot and are thrown away. They are not bothered at this loss because they have enough profits already to enable them go back to the market. Those who can not afford these prices are denied the food items and enormous resources are therefore wasted. Food is therefore not utilized (Asiabaka, 2010).

Agricultural production as observed in developing countries is affected by weather and climate which dictate outputs. We usually observe long spells of drought; torrential rainfall and flooding could seriously disrupt production and lead to fall in supply of agricultural commodities. Agricultural products in most cases require special handling. Agricultural products are often too perishable as seen in fresh vegetables, eggs, yam, potatoes, bananas, fresh milk etc. In addition, some of these products are bulky e.g. yams, potatoes, oranges etc and this pose transportation challenges. Hence, marketing of agricultural products involve a large number of people in the channel of distribution which include assemblers, transporters, bulk breakers and retailers (Yuba, 2007). The degree of involvement of middlemen in the trade channel is usually, implicitly or explicitly, explained by a functional argument. In other words, the role of middlemen is determined by their economic value for sellers and buyers. In the pre-industrial era the circumstances for involvement of middlemen in (international) trade were very favourable: industry was widely dispersed, the means of communication and transport were poor, and both production and transport were of a seasonal nature. Consequently, the middlemen prospered ( Driel, 2003) in the supply chain.

There are many functions to be carried out in moving the agricultural products from producers to customers. Each of these functions requires funding and, often experience and specialist knowledge and expertise. The central function of the middlemen is to absorb part of the risks, buyers and sellers face (Driel, 2003). The tasks performed by middlemen to fulfill their functions are manifold and can be described in different ways. Four dimensions of conditions of supply and demand are distinguished which include, place, time, quantity, and quality. If there are large gaps between these conditions, uncertainty for buyers and sellers is relatively high. Middlemen are particularly suited to reduce this uncertainty by bridging the gaps in the supply chain (Rao, 2008). It has been observed that stability in food availability is not always guaranteed and as a result of this uncertainty, the possibility of realizing economies of scale is crucial for buyers and sellers in deciding for or against direct trade. In certain circumstances, middlemen are able to reach economies of scale which buyers and sellers cannot create themselves. These economies of scale refer to the process of distribution. To explain the involvement of middlemen by means of their function is a complicated matter because they fulfill different needs at the same time (Campbell, 1991). The specific objectives of this paper are to:

$>$ determine the source/point at which middlemen obtain their goods.

$>$ ascertain farm gate price and that fixed by middlemen for the purchase of the items bought at farm gate prices. 
$>$ check through the respondents, government's intervention so as to ameliorate the problem of middlemen.

\section{METHODOLOGY}

This study was conducted through field survey in Imo State, Nigeria. Respondents were randomly selected from the three major cities / zones namely Okigwe, Orlu and Owerri respectively. The respondents were predominantly farmers and about $40 \%$ of them had undergone formal education. A total of 500 respondents were randomly selected and interviewed from each zone and in all 1500 respondents were involved in the study from January to July 2010.This was done to ensure that defective data were avoided. Data collected were analyzed using frequency distribution and percentages. Bar charts were used to represent the percentage levels in the three agro-ecological zones.

\section{RESULTS AND DISCUSSION}

The results of the study showed that $81.1 \%$ of the respondents affirmed that middlemen buy the farmer's produce directly from the point of harvest and further dictate the pace of the distribution channel. The reason for this high percentage of respondent's affirmation is as a result of the fact that middlemen are the bulk buyers and in some cases they assemble adequate volume of raw products and convert them into more marketable forms. These assembly costs included transportation of agricultural products from the farm to an assembly point where products are stored, graded, or converted into more marketable forms. There is no doubt therefore that additional marketing and distribution functions may need to be accomplished such as managing inventory, filling orders, transporting products to customers, or providing other related customer services. These services are very tasking for a farmer who primarily is at the production sector in the channel of distribution.

In the same vein, about $64 \%$ of the respondents strongly agreed that the farmer often sells with low price regimes translating to very marginal income as a result of seasonality of production which gives room to abundance of farm products and the attendant crash in price and bargaining power. Another strong factor which influenced the decision of the respondents was that farmers are highly challenged by spoilage and quality depreciation during harvest due to the absence of processing and storage facilities to store excess produce for future use. The result further showed that over $89 \%$ of the respondents agreed that the middle man is the ultimate risk bearer. Hence, he raises prices in order to ensure profits after integrating the numerous services he has rendered in the distribution channel.

It was observed further that the middle men's outrageous price regime over stretches the financial burden of the final consumers and thus, spreading poverty and food crises. This price variation suggested an exploitative role of the middle men in the distribution channel and hence exacerbating the global food crises. This agreed with Rao (2008) who argued that in the modern world, it has become challenging with the involvement of middlemen and commission agents who keep their margins and move the produce further. We also observed that the more the number of middle men, the higher the selling cost as each intermediary adds a cost on the transaction.

The results of the study showed that $72.9 \%$ of the respondents agreed that government has done very little to encourage farmers and save them from the over bearing influence of the middle men in the agricultural product supply chain. The respondents observed that middlemen became very necessary in the supply chain due to non intervention of government to farmer's limitations and challenges. These challenges and limitations were identified as inadequate storage and processing facilities, inadequate accesses to market information, inconsistencies of weather and climate conditions as a result of climate change and the literacy level of farmers. 
In addition, $75.6 \%$ of the respondents agreed that climate change was responsible for seasonal fluctuations which unarguably are affecting crop and animal yields. However; post harvest losses could be mitigated using technological improvements which the government can undertake and sustain. From the study, we observed that government has not done enough to encourage "disintermediation" (the removal of intermediaries in the supply chain or the cutting out of the middleman"). Thus, the gain margins of farmers would increase favorably if through government intervention, a new distribution network is generated to connect the farmers directly to consumers. The activities of middle men who buy up from farmers at considerably low prices and later hoard to create artificial scarcity so as to sell at higher prices will be eliminated totally or minimized if such distribution network is put in place. This also agreed with Rao (2008). Furthermore, $75.6 \%$ of the respondents strongly advocated that government should provide soft loans to the farmers at low interest rate so that they will be freed from the clutches of local moneylenders who squeeze them, and the restructuring of the marketing boards to checkmate the excesses of middle men.

\section{CONCLUSION AND RECOMMENDATIONS}

The world is now gearing up to meet the millennium development goals by 2015 that includes reducing global poverty by at least half. The resources required to meet the Millennium Development Goals (MDGs) including eradication of extreme poverty and hunger by 2015 are available but only require judicious management and distribution. It is thus highlighted that unless hunger is eradicated through the increased production and fair distribution of resources, guarantee of access to food for the absolute poor and food security, it would be a mirage for the global community to achieve the lofty goal of meeting the minimum basic needs of people by 2015 .

The study observed that there were several challenges involved in marketing of agricultural products. Expectedly, price control mechanisms will be put in motion to give the farmers a good pricing for their produce and product standardization and grading which have now become the functions of the middle men will cease to be. In addition, the board will be buying up surplus during harvest time and release same when there is glut. This singular action will mitigate food crisis on the long run, guarantee food security and successfully reduce to the barest minimum the over bearing activities of the middle men in the food distribution channel. It was equally observed that middle men have so much entrenched themselves in the distribution channel to milk dry the farmers and the consumers. Challenges facing farming and farmers included limited access to market information, low literacy level, absence of infrastructural framework and non commitment of government to agriculture which government intervention can solve to eradicate poverty and reduce food insecurity. There is the need to back up policies with actions.

In general, a critical view shows that global food production is sufficient to feed the world population, but it is unfortunate that hunger still exists and tens of thousands of people die of hunger and malnutrition annually in the world. Worst still is that developed economies of the world dump the surplus food into the ocean while other parts of the world starve and suffer from chronic hunger. The question has gone beyond how much the world produces but rather fair access to production resources for the people from the lowest economic strata. This issue calls for judicial distribution of food to all. It is highly recommended that intervention policies should be initiated by government to scale down the over bearing influence of the middle men who happen to be core capitalists in the food distribution channel and hence check food insecurity and food crisis. 


\section{REFERENCES}

Asiabaka, C.C. (2010) Scaling up Agricultural technology for food security and poverty reduction: whose knowledge counts, the Farmer or the Scientist? $16^{\text {th }}$ Inaugural Lecture of Federal University of Technology, Owerri.

Braun, J.von, H. Bouis, S. Kumer and R. Padaya-Lorch (1992) Improving food security of the poor: concept, policy and programmes. Washington, D.C. International Food Policy Research Institute (IFRRI).

Campbell, C.C. (1991) Food security: A Nutritional outcome of predictor variable? Journal of Nutrition 122(3)408-415

Driel, Hugo Van (2003) The role of middlemen in the international coffee trade since 1870: The Dutch case.

Esonu, B.O. (2009) Unconventional feed resources for livestock development and food security: paradigms for Nigeria livestock Industry. $14^{\text {th }}$ Inaugural Lecture of Federal University of Technology, Owerri.

Rao, M.S. (2008) Problems and prospects in Agricultural marketing: Where knowledge is wealth.profmsr7@gmail.com.

United States Agency for International Development \{USAID\}(1995). Food Aid and Food Security: Policy Determination PNAAV 468, Washington, D.C.

Yuba Nath Lamsal (2007) Agriculture, food security and poverty alleviation

Table 1: Levels of respondents at the agro-ecological zones

\begin{tabular}{|c|c|c|c|c|c|c|}
\hline & \multicolumn{2}{|c|}{ Okigwe } & \multicolumn{2}{|c|}{ Orlu } & \multicolumn{2}{|c|}{ Owerri } \\
\hline & Freq & $\%$ & Freq & $\%$ & Freq & $\%$ \\
\hline Middlemen buy from farmers at point of harvest & 415 & 83.0 & 387 & 77.4 & 411 & 82.2 \\
\hline Middlemen are the undisputed bulk buyers & 358 & 70.8 & 367 & 73.4 & 389 & 77.4 \\
\hline $\begin{array}{l}\text { Middlemen process raw materials to other } \\
\text { marketable forms }\end{array}$ & 320 & 64.0 & 400 & 80.0 & 460 & 92.0 \\
\hline $\begin{array}{l}\text { Farmers sell at considerable low price to the } \\
\text { middle men }\end{array}$ & 300 & 60.0 & 293 & 58.7 & 340 & 68.0 \\
\hline $\begin{array}{l}\text { Farmers are highly challenged by seasonality } \\
\text { and climate }\end{array}$ & 333 & 66.7 & 413 & 82.7 & 386 & 77.3 \\
\hline $\begin{array}{l}\text { Quality depreciation and spoilage of products usu } \\
\text { the farmer to dispose off wares at give away price }\end{array}$ & $\begin{array}{l}\text { y forc } \\
\text { o the }\end{array}$ & & & & & \\
\hline middlemen & 423 & 84.7 & 326 & 65.3 & 340 & 68.0 \\
\hline Midd & rs 483 & 96.7 & 446 & 89.3 & 426 & 85.3 \\
\hline Middlemen activities exacerbate food crisis & 466 & 93.3 & 440 & 88.0 & 433 & 86.7 \\
\hline $\begin{array}{l}\text { Government has done little or nothing to genuine } \\
\text { assist farmers }\end{array}$ & 400 & 80.0 & 360 & 72.0 & 333 & 66.7 \\
\hline
\end{tabular}

Source: Field survey data 2010 


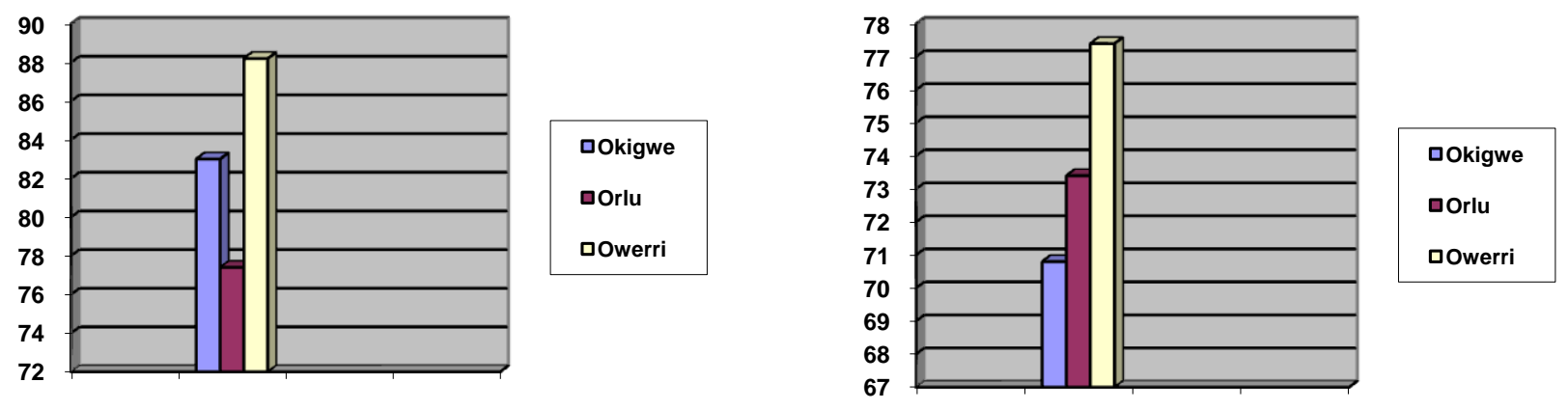

Fig 1: Middlemen buy from farmers at point of harvest

Fig 2: Middlemen are the undisputed bulk buyers
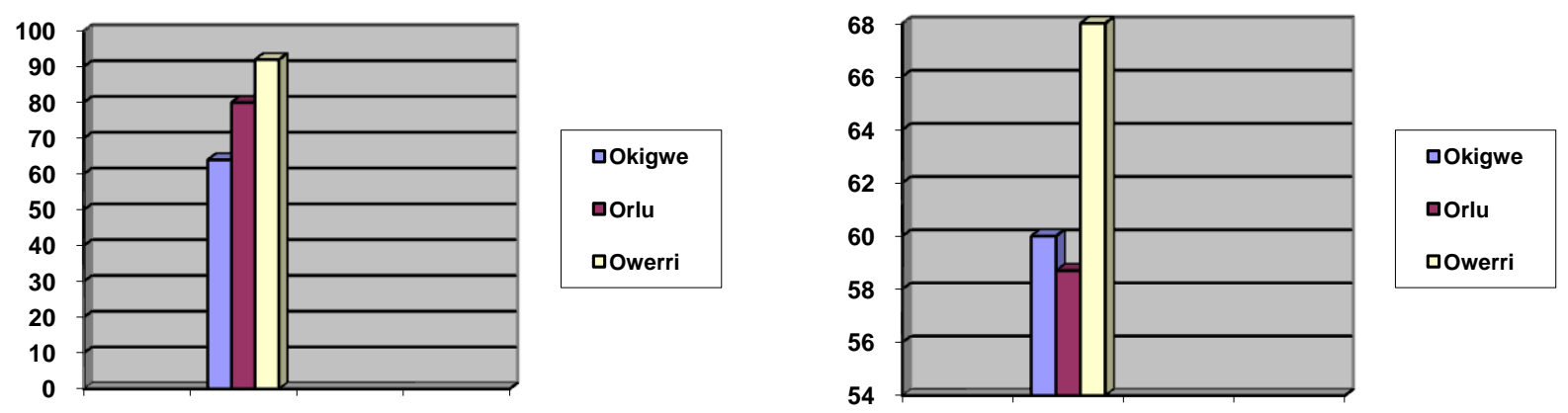

Fig 3 : Middlemen process raw materials to other forms

Fig 4 : Farmers sell at considerable low price to middlemen

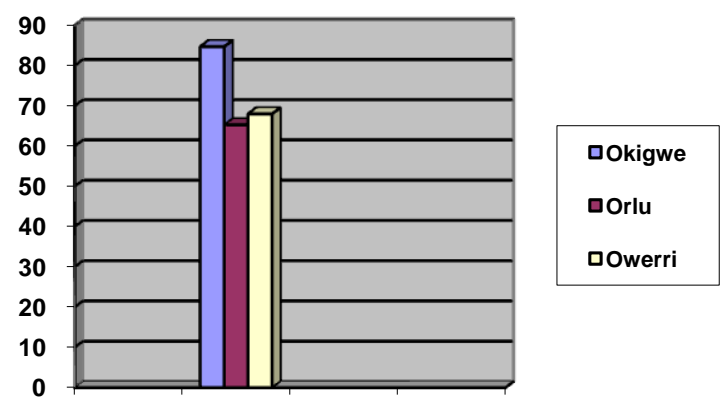

Fig 5: Farmers are highly challenged by seasonality and climate

Fig 6: Quality depreciation and product spoilage affect pricing 
Journal of Agriculture and Social Research (JASR) VOL. 10, No. 2, 2010
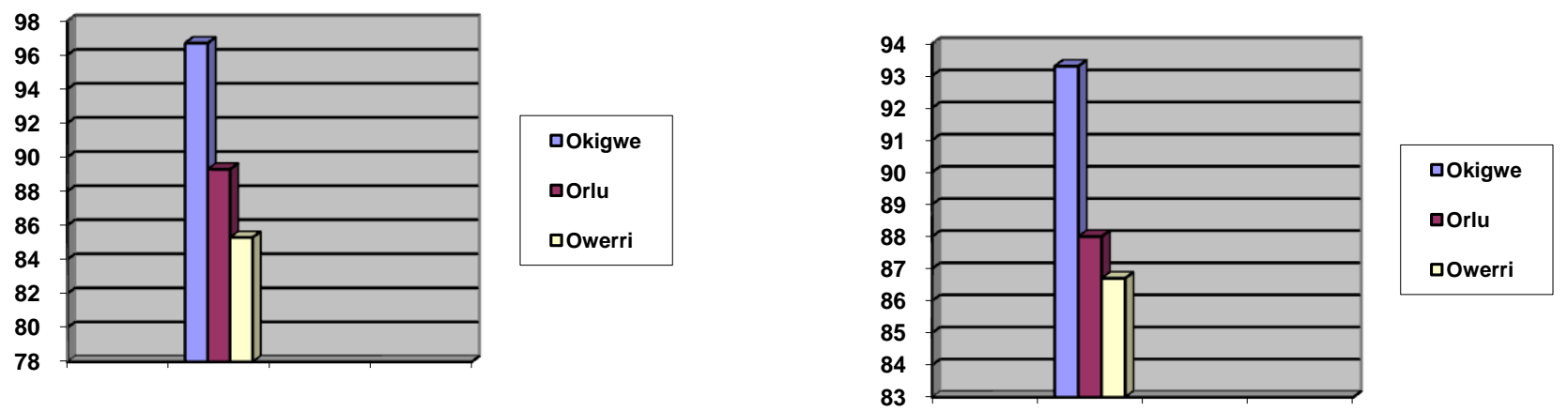

Fig 7: Middlemen sell at outrageous price to the consumers crisis

Fig 8: Middlemen activities exacerbate food

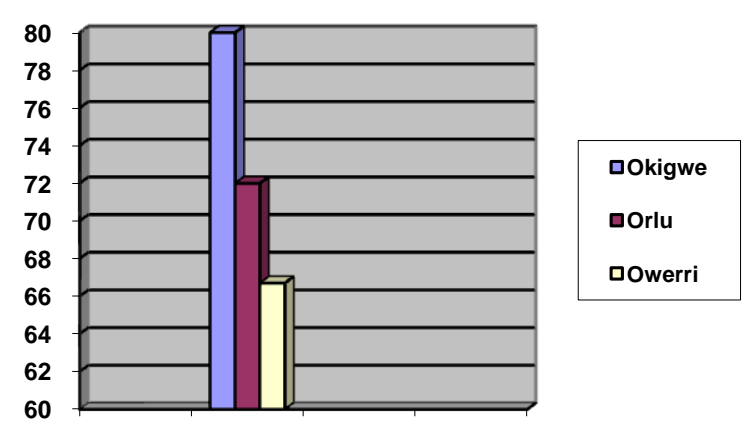

Fig 9: Government has done little or nothing to genuinely assist farmers 